\title{
ASO Visual Abstract: Neoadjuvant Endocrine Therapy and Delays in Surgery for Ductal Carcinoma in Situ: Implications for the Coronavirus Pandemic
}

Austin D. Williams, MD, MSEd ${ }^{1}$, Cecilia Chang, $\mathrm{MS}^{2}$, Elin R. Sigurdson, MD, $\mathrm{PhD}^{3}$, Chihsiung Wang, $\mathrm{PhD}^{2}$, Allison A. Aggon, $\mathrm{DO}^{3}$, Maureen V. Hill, $\mathrm{MD}^{3}$, Andrea Porpiglia, $\mathrm{MD}^{3}$, and Richard J. Bleicher, $\mathrm{MD}^{3}$

${ }^{1}$ Department of Surgery, Lankenau Medical Center, Wynnewood, PA; ${ }^{2}$ Research Institute, NorthShore University HealthSystem, Evanston, IL; ${ }^{3}$ Department of Surgical Oncology, Fox Chase Cancer Center, Philadelphia, PA

This analysis (https://doi.org/10.1245/s10434-021-1088 3-5) of a pre-pandemic cohort found that neoadjuvant endocrine therapy (NET) used as a bridge to surgery during the SARS-CoV2 pandemic may offer protection from cancer invasion for patients with ductal carcinoma in situ (DCIS) who experience a delay in surgery.

\section{Neoadjuvant endocrine therapy and delays in surgery for ductal carcinoma in situ: implications for the coronavirus pandemic}

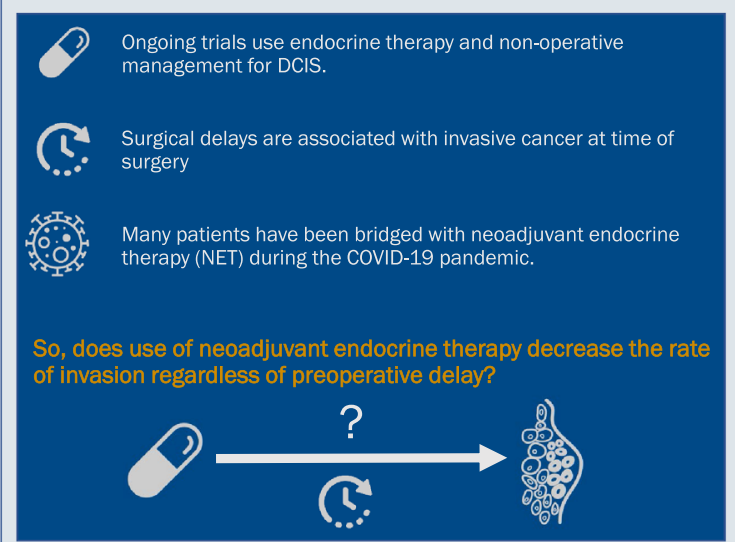

Williams et al. Ann Surg Oncol.

Visual Abstract @adwilliams5 and @RichardBleicher for @AnnSurgOncol

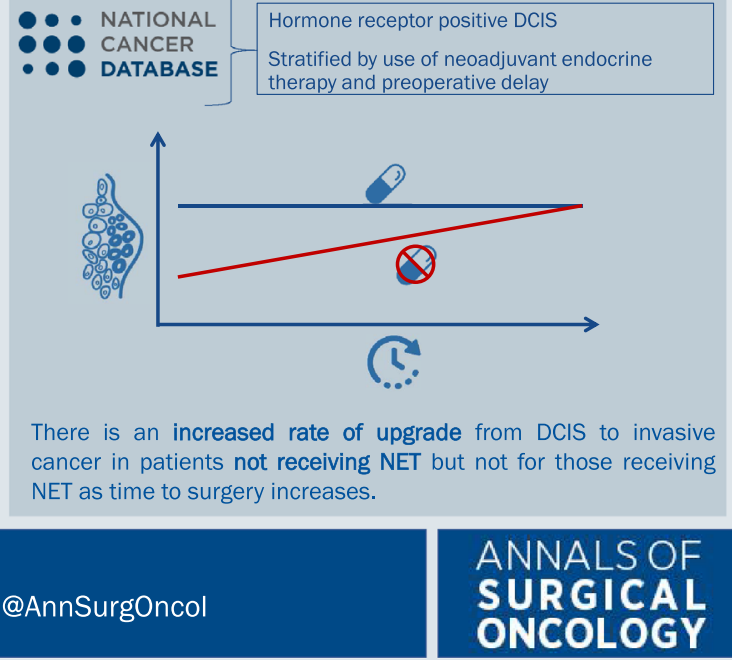

Publisher's Note Springer Nature remains neutral with regard to jurisdictional claims in published maps and institutional affiliations.

(C) Society of Surgical Oncology 2021

R. J. Bleicher, MD

e-mail: Richard.Bleicher@fccc.edu 